\title{
PENAPISAN PENYAKIT HIPERTENSI, DIABETES MELITUS, DAN DEMENSIA PADA LANJUT USIA DI PANTI SOSIAL TRESNA WERDHA PUSPAKARMA MATARAM
}

\section{Screening of Hypertension, Diabetes Mellitus, and Dementia among Elderly Residing in Tresna Werdha Puspakarma Social Centre, Mataram}

\author{
Novrita Padauleng ${ }^{1}$, Ardiana Ekawanti ${ }^{1}$, Herpan Syafii Harahap ${ }^{1,3}$, Ida Ayu Eka Widiastuti ${ }^{1}$, \\ Deasy Irawati ${ }^{* 1,2}$ \\ ${ }^{1}$ Bagian Biomedik Fakultas Kedokteran Universitas Mataram, ${ }^{2}$ Bagian IImu Kesehatan \\ Masyarakat Fakultas Kedokteran Universitas Mataram, ${ }^{3}$ Bagian Saraf Fakultas Kedokteran \\ Universitas Mataram
}

JI. Pendidikan No. 37, Kota Mataram, Provinsi NTB, 83125

*Alamat korespondensi: deasy.irawati@unram.ac.id

(Tanggal Submission: 28 July 2020, Tanggal Accepted: 27 November 2020)

\begin{abstract}
ABSTRAK
Peningkatan usia harapan hidup tidak hanya membawa konsekuensi bertambahnya penduduk lanjut usia (lansia), tetapi mempunyai implikasi terhadap masalah kesehatan yang ditimbulkan. Hipertensi, diabetes melitus, dan demensia adalah beberapa penyakit dengan prevalensi yang tinggi pada kelompok populasi ini. Adanya proses penuaan, turut berpengaruh terhadap komplikasi yang timbul serta tatalaksana yang tentunya berbeda dengan penderita pada kelompok usia lainnya. Kegiatan pengabdian pada masyarakat ini bertujuan untuk melakukan penapisan (screening) penyakit hipertensi, diabetes melitus dan demensia pada lansia. Metode pelaksanaan kegiatan meliputi penapisan hipertensi, diabetes melitus, dan demensia pada peserta lanjut usia di Panti Sosial Tresna Werdha Puspakarma Mataram. Penapisan hipertensi, diabetes melitus, dan demensia dilakukan dengan pemeriksaan tekanan darah, glukosa darah puasa, serta fungsi kognitif menggunakan instrumen MoCA-INA. Hasil penapisan menunjukkan bahwa 35\% lansia mengalami prehipertensi, 36,3\% lansia mengalami hipertensi derajat 1 dan 12,5\% lansia terdeteksi hipertensi derajat 2 . Sebanyak 23,8\% lansia memiliki gula darah puasa $\geq 126 \mathrm{mg} / \mathrm{dl}$, dan gangguan fungsi kognitif terdeteksi pada $83 \%$ lansia. Berdasarkan hasil tersebut, maka populasi lanjut usia yang menjadi peserta kegiatan pengabdian ini, sebagian besar mengalami hipertensi dan terutama penurunan fungsi kognitif, sementara penapisan diabetes dengan GDP perlu dilengkapi anamnesis terkait gejala klinis yang menyertai. Upaya ini merupakan salah satu solusi strategi yang tepat, agar dapat direncanakan tatalaksana yang tepat sesuai dengan usia peserta.
\end{abstract}

Kata kunci: Lanjut usia, hipertensi, diabetes, demensia 


\section{PENDAHULUAN}

Seiring dengan peningkatan pelayanan kesehatan yang disertai dengan peningkatan standar hidup, usia harapan hidup penduduk di negara maju maupun negara berkembang, termasuk Indonesia, semakin meningkat. Data dari Badan Perencanaan Pembangunan Nasional Tahun 2013, usia harapan hidup di Indonesia (laki-laki dan perempuan) meningkat dari 70,1 tahun pada periode 2010-2015 menjadi 72,2 tahun pada periode $2030-2035$. Hasil proyeksi juga menunjukkan bahwa jumlah penduduk Indonesia selama 25 tahun ke depan akan mengalami peningkatan dari 238,5 juta pada tahun 2010 menjadi 305,8 juta pada tahun 2035, dengan peningkatan jumlah penduduk berusia lebih dari 65 tahun sebesar 5,6 \% (BPS, 2013). Peningkatan populasi lanjut usia (lansia) membawa masalah yang tidak dapat dihindari, yaitu proses penuaan. Proses ini mengakibatkan gangguan fungsi organ dan peningkatan prevalensi berbagai penyakit yang berkaitan dengannya. Beberapa penyakit tersebut diantaranya hipertensi, diabetes melitus, dan demensia, dengan risiko komplikasi yang tinggi dan sukar diatasi, serta sangat mempengaruhi kualitas hidup penderita (WHO, 2015).

Hipertensi merupakan faktor risiko penting mortalitas dan morbiditas kardiovaskular, terutama pada lansia. Berdasarkan Seventh Report of the Joint National Committee on prevention, Detection, Evaluation and Treatment of High Blood Pressure (JNC-7), dua pertiga populasi yang berusia lebih dari 65 tahun mengalami hipertensi (Chobanian, et al. 2003). Hal ini disebabkan oleh beberapa faktor yang berkaitan dengan proses penuaan pada berbagai sistem organ, diantaranya menurunnya elastisitas dinding arteri, gangguan regulasi neurohormonal dan autonom, serta penurunan fungsi ginjal (Epstein 1996; Beck 2000; O'Rourke, et al. 2007).

Dampak proses penuaan yang lain yaitu perubahan metabolisme karbohidrat seperti penurunan sekresi insulin dan resistensi insulin. Adanya perubahan tersebut disertai predisposisi genetik, menjadi penyebab meningkatnya insidensi diabetes melitus pada kelompok populasi ini. Penyakit ini dapat dijumpai pada $20 \%$ populasi berusia 75 tahun (Meneilly, et al. 2001). Menurut American Diabetes Association (ADA), diabetes melitus (DM) merupakan suatu kumpulan penyakit metabolik dengan karakteristik peningkatan kadar glukosa di dalam darah atau hiperglikemia, yang terjadi karena kelainan sekresi insulin, kerja insulin, atau keduanya (ADA, 2006). Penyakit ini memiliki fase pre-klinik asimptomatis yang cukup lama dan seringkali tidak terdeteksi. Hal tersebut menyebabkan lebih dari separuh penderita pada saat terdiagnosa penyakit ini, telah memiliki satu atau lebih komplikasi, seperti retinopati, neuropati, penyakit kardiovaskuler, stroke, dan sebagainya. Penelitian yang dilakukan oleh The International Diabetes Management Practices Study (IDMPS) pada tahun 2006 di Indonesia, sebanyak 48\% penderita diabetes melitus tipe 2 juga mengalami hipertensi (Soewondo, 2011).

Selain hipertensi dan diabetes, peningkatan prevalensi demensia merupakan masalah lain yang timbul akibat peningkatan populasi lansia (WHO, 2015). Demensia adalah sindrom penurunan fungsi kognitif, seperti memori, visuo-spasial, atensi, dan lainnya. Penderita demensia mengalami gangguan aktivitas sosial dan profesional yang tercermin dalam aktivitas hidup keseharian (Laurin, et al. 2001).

Berbagai komplikasi serius terkait penyakit hipertensi, dan diabetes melitus, serta penurunan fungsi kognitif pada penderita demensia tentunya memiliki dampak yang besar bagi kualitas hidup penderita, terutama lansia. Salah satu lembaga yang memberikan pelayanan kesejahteraan sosial pada lansia adalah panti sosial (RI, 2010). Panti Sosial yang terdapat di Mataram adalah Panti Sosial Tresna Werdha Puspakarma Mataram, sehingga lembaga 
ini menjadi sarana yang tepat untuk dilakukan penapisan ketiga penyakit di atas. Latar belakang ini menjadi alasan pentingnya upaya penapisan sebagai salah satu strategi yang tepat untuk merencanakan upaya tatalaksana yang tepat bagi kelompok populasi ini. Terkait dengan hal tersebut, kami bermaksud mengadakan penapisan (screening) penyakit hipertensi, diabetes melitus dan demensia di Panti Sosial. Kegiatan ini bermanfaat untuk meningkatkan upaya deteksi dini beberapa penyakit pada populasi lansia, agar dapat direncanakan tatalaksana yang tepat sesuai dengan permasalahan kesehatan pada kelompok populasi tersebut.

\section{METODE KEGIATAN}

Kegiatan penapisan dilaksanakan di Panti Sosial Tresna Werdha Puspakarma Mataram dengan peserta adalah lansia, yaitu individu yang berusia lebih dari 60 tahun (RI, 1998). Target peserta sebanyak 80 orang, dengan metode pelaksanaan kegiatan yang akan dilakukan dalam 3 jenis penapisan, yaitu penapisan hipertensi, diabetes mellitus dan demensia.

Penapisan hipertensi dilakukan dengan pemeriksaan tekanan darah metode auskultasi, yaitu mengukur tekanan darah sistole dan diastole pada arteri brachialis menggunakan tensimeter. Hipertensi merupakan peningkatan tekanan darah sistolik $\geq 140 \mathrm{mmHg}$ dan atau tekanan darah diastolik $\geq 90 \mathrm{mmHg}$ pada pemeriksaan yang berulang (Tabel 1 ).

Tabel 1. Klasifikasi tekanan darah berdasarkan JNC 7 (Chobanian, et al. 2003)

\begin{tabular}{ccc}
$\begin{array}{c}\text { Klasifikasi Tekanan } \\
\text { Darah }\end{array}$ & $\begin{array}{c}\text { Sistole } \\
(\mathrm{mmHg})\end{array}$ & $\begin{array}{c}\text { Diastole } \\
(\mathrm{mmHg})\end{array}$ \\
\hline Normal & $<120$ & $<80$ \\
Prehipertensi & $120-139$ & $80-89$ \\
Hipertensi Stage 1 & $140-159$ & $90-99$ \\
Hipertensi Stage 2 & $\geq 160$ & $\geq 100$ \\
\hline
\end{tabular}

Penapisan diabetes mellitus dilakukan dengan pemeriksaan kadar glukosa darah puasa (GDP). Sampel darah diambil dari vena mediana cubiti. Pemeriksaan kadar glukosa darah dilakukan di Laboratorium Hepatika dengan menggunakan alat spektrofotometer COBAS dengan nilai rujukan terlampir di bawah ini (Tabel 2).

Tabel 2. Nilai rujukan kadar GDP pada penapisan dan diagnosa DM (ADA, 2006)

\begin{tabular}{ccccc}
\hline Kadar Glukosa & Sampel & Bukan DM & Belum pasti DM & DM \\
\hline GDP & Plasma vena & $<100$ & $100-125$ & $\geq 126$ \\
$(\mathrm{mg} / \mathrm{dl})$ & Darah kapiler & $<90$ & $90-99$ & $\geq 100$ \\
\hline
\end{tabular}

Penapisan demensia dilakukan dengan pemeriksaan fungsi kognitif yang menggunakan instrumen Montreal Cognitive Assessment dalam versi Bahasa Indonesia (MoCA-INA). Pemeriksaan ini menilai berbagai domain kognitif, yaitu visuospasial, penamaan, memori, atensi, bahasa, berpikir abstrak, memori tertunda, dan orientasi dalam waktu 10 menit. Skor total pada pemeriksaan ini adalah 30, dengan skor $\geq 26$ menunjukkan fungsi kognitif normal (Trzepacz, et al. 2015).

\section{HASIL DAN PEMBAHASAN}

Kegiatan ini dilaksanakan di Panti Sosial Tresna Werdha Puspakarma, Mataram NTB. Sebanyak 80 peserta mengikuti serangkaian pemeriksaan penapisan hipertensi, diabetes melitus, dan demensia, yang meliputi tekanan darah, gula darah puasa, serta MoCA-INA (Gambar 1). 


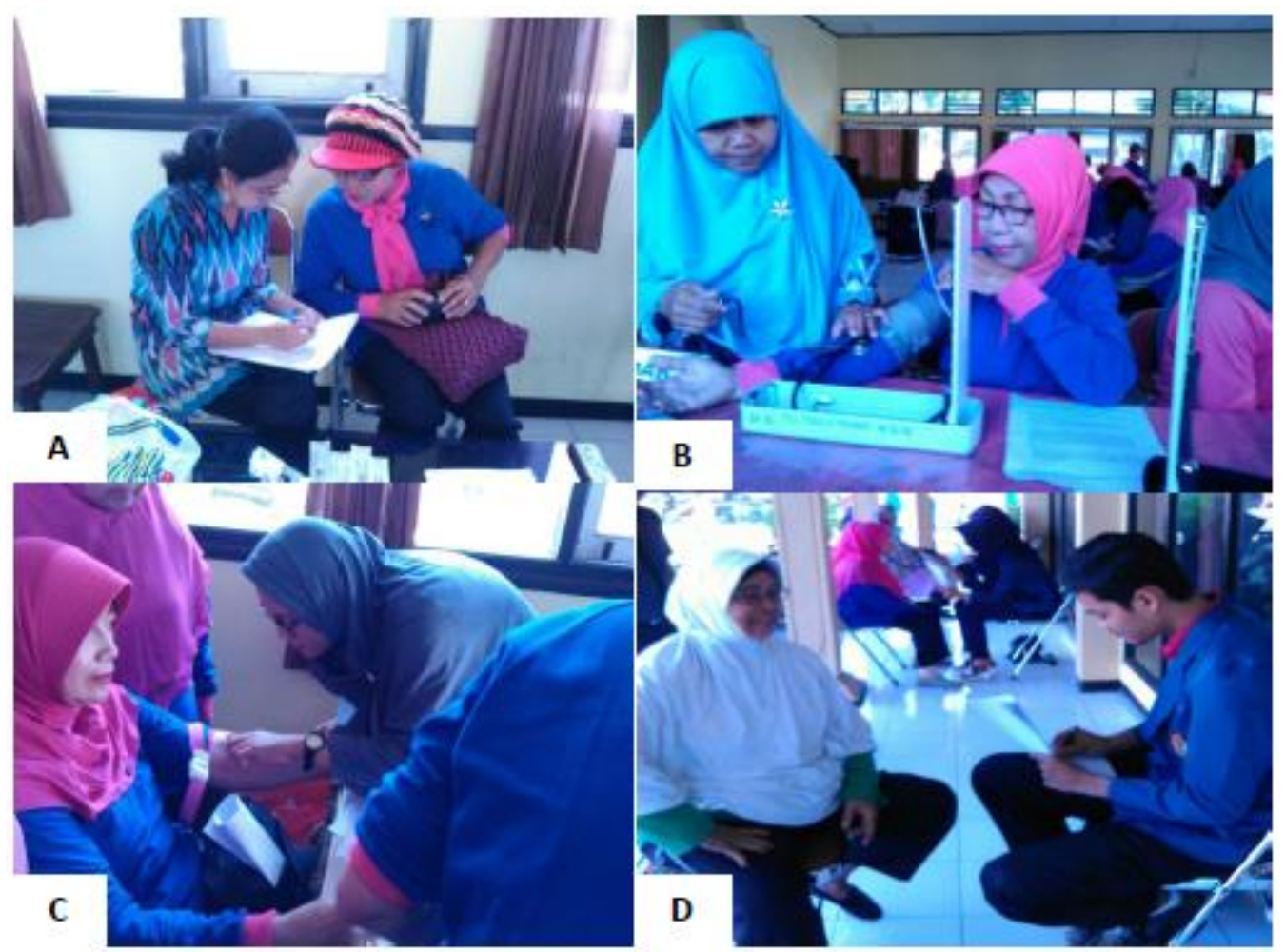

Gambar 1. Kegiatan pengabdian kepada masyarakat di Panti Sosial Tresna Werdha Puspakarma. (A). Pendataan identitas peserta, (B). Pemeriksaan tekanan darah, (C) Pemeriksaan GDP, (D) Pemeriksaan MoCA-INA

\section{Penapisan Diabetes Melitus}

Pemeriksaan GDP pada 80 peserta menunjukkan bahwa 61 (76,3\%) peserta memiliki gula darah puasa normal, sementara 19 peserta $(23,8 \%)$ memiliki gula darah puasa $\geq 126 \mathrm{mg} / \mathrm{dl}$. Sebuah survey, HANES III (Health and Nutrition Survey) menunjukkan bahwa $20 \%$ populasi menderita diabetes pada usia 75 tahun, dimana setengah dari populasi tersebut tidak menyadari kondisi diabetes yang dialami. Insidensi diabetes meningkat secara progresif seiring dengan pertambahan usia. Hal ini disebabkan perubahan metabolisme karbohidrat, seperti gangguan pelepasan insulin dan resistensi insulin. Faktor lain yang mempengaruhi adalah konsumsi makanan yang mengandung tinggi lemak jenuh serta rendah karbohidrat kompleks. Kurangnya aktivitas fisik dan rendahnya kadar testosterone pada laki-laki, serta tingginya kadar hormon tersebut pada perempuan juga mempengaruhi terjadinya diabetes pada populasi lanjut usia. Selain itu, indeks massa tubuh juga mempengaruhi patogenesis diabetes, dimana individu lanjut usia yang menderita diabetes tipe 2 dengan indeks massa tubuh kurus menunjukkan gangguan sekresi insulin, sementara individu lansia dengan obesitas menunjukkan resistensi terhadap insulin. Berdasarkan keterangan di atas, maka intervensi faktor yang dapat dimodifikasi seperti pola makan, aktivitas fisik, indeks massa tubuh penting untuk dilakukan.

\section{Penapisan Hipertensi}

Dengan berpedoman pada klasifikasi tekanan darah pada dewasa menurut JNC VII, maka hasil pemeriksaan tekanan darah para lansia di Panti Werdha Puspakarma, sebagian besar lansia memiliki 
gangguan tekanan darah dengan perincian kategori prehipertensi sebanyak 28 orang (35\%), hipertensi derajat 1 sebanyak 29 orang (36,3\%), dan kategori hipertensi derajat 2 sebanyak 10 orang $(12,5 \%)$. Hanya 13 orang $(16,2 \%)$ yang memiliki tekanan darah normal. Bertambahnya usia akan meningkatkan risiko terhadap peningkatan tekanan darah akibat proses degenerasi. Adanya faktor risiko lain selain usia, misalnya pola makan, kebiasaan berolahraga, merokok, stres, penyakit kardiovaskuler, dapat memperbesar kemungkinan seseorang mengalami hipertensi.

Berbagai upaya preventif untuk mencegah hipertensi dapat dilakukan, antara lain mengatur pola dan jenis makanan, mengontrol berat badan, berolahraga, terapi relaksasi, menghindari atau berhenti merokok, menghindari minuman keras ,dan istirahat yang cukup. Konsumsi makanan dianjurkan rendah lemak dan kaya serat, seperti roti dari biji-bijian utuh, beras merah, serta buah dan sayuran. Mengurangi konsumsi garam dalam makanan, setidaknya tidak lebih dari 5 gram garam per hari (sekitar satu sendok teh). Walaupun hanya beberapa kilogram, menurunkan berat badan akan membuat perbedaan besar pada tekanan darah dan kesehatan secara keseluruhan. Untuk menurunkan tekanan darah dan menjaga jantung serta pembuluh darah dalam kondisi baik, olahraga dan beraktivitas secara rutin dan teratur sangat perlu dilakukan. Aktivitas fisik yang bermanfaat untuk kesehatan lansia sebaiknya memenuhi kriteria FITT (frequency, intensity, time, type). Lansia direkomendasikan melakukan aktivitas fisik setidaknya selama 30 menit pada intensitas sedang hampir setiap hari dalam seminggu. Berjalan, berkebun, naik turun tangga dapt dilakukan untuk mencapai tujuan tersebut. Sementara itu, jenis terapi relaksasi yang dapat dilakukan lansia antara lain adalah yoga dan meditasi. Terapi relaksasi bertujuan untuk membantu mengendalikan stres. Mengendalikan stres juga dapat dicapai dengan melakukan hobi dan berekreasi. Rokok tidak menjadi penyebab langsung terjadinya hipertensi, namun merokok dapat memicu terjadinya penyempitan arteri sehingga dapat mempertinggi risiko penyakit jantung atau paru-paru. Selain itu, mengkonsumsi minuman keras secara berlebihan dapat mempertinggi risiko tekanan darah tinggi. Modifikasi pola hidup lain adalah dengan beristirahat yang cukup, sekitar 6-7 jam per hari dibutuhkan untuk tetap menjaga kesehatan dan kebugaran. Dengan kondisi fisik yang baik, maka stres yang merupakan salah satu penyebab hipertensi dapat dihindari.

\section{Penapisan Demensia}

Dalam kegiatan ini, peserta yang menjalani evaluasi fungsi kognitif global dengan menggunakan instrumen Montreal Cognitive Assessment Indonesia version (MoCA-INA) sebanyak 49 orang dengan rerata usia 65 tahun. Pada pemeriksaan fungsi kognitif global didapatkan rerata skor MoCAINA sebesar 21,1 dan nilai rerata tersebut dibawah nilai normal. Seperti diketahui, individu dinyatakan mengalami gangguan fungsi kognitif global jika memiliki skor MoCA-INA <26 dan memiliki fungsi kognitif normal jika memiliki skor MoCA-INA $\geq 26$. Sewaktu peserta dikelompokkan berdasarkan klasifikasi skor MoCA-INA, sebanyak 83\% lansia mengalami gangguan fungsi kognitif (Gambar 2). Berdasarkan data tersebut dapat disimpulkan bahwa sebagian besar subjek mengalami gangguan fungsi kognitif, konsisten dengan rerata skor MoCA-INA yang telah dipaparkan sebelumnya. 


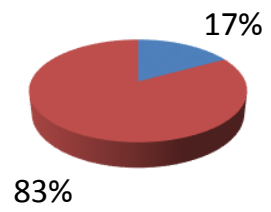
Skor MoCA-INA Normal
- Skor Mo-CA INA Rendah

Tingkat Pendidikan

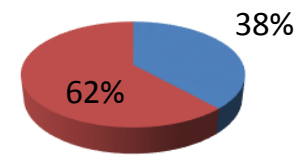

Tingkat Pendidikan $<12$ tahun

Gambar 2. Diagram pie proporsi hasil pemeriksaan MoCA-INA dan proporsi peserta berdasarkan tingkat pendidikan

Fungsi kognitif seseorang dipengaruhi oleh cognitive reserve yang dimilikinya. Salah satu faktor penting yang menentukan tingginya cognitive reserve seseorang adalah tingkat pendidikan yang dimilikinya. Dalam kegiatan ini, tingkat pendidikan subjek dibagi menjadi 2 kelompok, yaitu kelompok subjek dengan tingkat pendidikan $<12$ tahun dan $\geq 12$ tahun. Sebanyak 38\% lansia memiliki riwayat pendidikan $<12$ tahun (Gambar 2).

Faktor pendorong selama kegiatan pengabdian ini adalah antusiasme dan kerjasama pihak pengelola Panti Sosial Tresna Werdha Puspakarma Mataram. Pihak pengelola sangat mendukung dan bekerjasama dalam kegiatan ini dan berharap bahwa kegiatan ini bersifat berkelanjutan. Adapun faktor penghambat tidak ada selama berlangsungnya kegiatan ini.

\section{KESIMPULAN DAN SARAN}

Kegiatan pengabdian ini dapat menapis peserta yang mengalami hipertensi, diabetes melitus,dan demensia dengan pemeriksaan yang sederhana, meliputi tekanan darah, glukosa darah puasa, serta fungsi kognitif menggunakan instrumen MoCA-INA. Penapisan ini adalah salah satu solusi strategi agar dapat direncanakan tatalaksana yang tepat bagi peserta populasi lanjut usia di Panti Sosial
Tresna Werdha Puspakarma Mataram yang terdeteksi menderita hipertensi, diabetes, ataupun demensia.

\section{UCAPAN TERIMAKASIH}

Ucapan terimakasih disampaikan penulis kepada Lembaga Penelitian Universitas Mataram yang telah mendanai penelitian ini dari dana DIPA BOPTN 2017, Panti Sosial Tresna Werdha Puspakarma Mataram, dan Laboratorium Hepatika yang telah membantu kegiatan penelitian ini.

\section{DAFTAR PUSTAKA}

ADA (2006). "Standards of Medical Care in Diabetes - 2006." Diabetes Care 29(suppl 1): s4.

Beck, L. H. (2000). "The aging kidney. Defending a delicate balance of fluid and electrolytes." Geriatrics 55(4): 26-8, 312.

BPS (2013). Proyeksi Penduduk Indonesia 20102035. Jakarta, BPS.

Chobanian, A. V., G. L. Bakris, et al. (2003). "The Seventh Report of the Joint National Committee on Prevention, Detection, Evaluation, and Treatment of High Blood 
Pressure: the JNC 7 report." JAMA 289(19): 2560-72.

Epstein, M. (1996). "Aging and the kidney." J Am Soc Nephrol 7(8): 1106-22.

Laurin, D., R. Verreault, et al. (2001). "Physical activity and risk of cognitive impairment and dementia in elderly persons." Arch Neurol 58(3): 498-504.

Meneilly, G. S. and D. Tessier (2001). "Diabetes in elderly adults." J Gerontol A Biol Sci Med Sci 56(1): M5-13.

O'Rourke, M. F. and J. Hashimoto (2007). "Mechanical factors in arterial aging: a clinical perspective." $\mathrm{J}$ Am Coll Cardiol 50(1): 1-13.

RI, K. S. (2010). Panduan perencanaan pembiayaan pencapaian standar pelayanan minimal (SPM) bidang sosial daerah Provinsi dan daerah Kabupaten/Kota. 80/HUK/2010. K. S. RI.
RI, P. (1998). Undang-undang Kesejahteraan lanjut usia. 13/1998. P. RI.

Soewondo, P. (2011). "Current Practice in the Management of Type 2 Diabetes in Indonesia: Results from the International Diabetes Management Practices Study (IDMPS)." Journal of the Indonesian Medical Association:

Majalah Kedokteran Indonesia 61(12): 474-81.

Trzepacz, P. T., H. Hochstetler, et al. (2015). "Relationship between the Montreal Cognitive Assessment and Mini-mental State Examination for assessment of mild cognitive impairment in older adults." BMC geriatrics 15: 107-107. WHO (2015). World report on ageing and health. Geneva, World Health Organization 